03,12

\title{
Неэмпирические расчеты структуры и устойчивости нанотрубок на основе монохалькогенидов галлия
}

\author{
() В.В. Карпов, А.В. Бандура, Р.А. Эварестов \\ Санкт-Петербургский государственный университет, \\ Санкт-Петербург, Россия. \\ E-mail: valerkarp@mail.ru
}

Поступила в Редакцию 5 февраля 2020 г.

В окончательной редакции 5 февраля 2020 г.

Принята к публикации 10 февраля 2020 г.

\begin{abstract}
Впервые неэмпирически рассчитаны зависимости энергии сворачивания и ширины запрещенной зоны ахиральных нанотрубок от их диаметра, полученных сворачиванием монослоев сульфидов и селенидов двухвалентного галлия. Расчеты выполнены по программе CRYSTAL17 с использованием атомного базиса в рамках гибридного метода теории функционала плотности с 13-процентным обменом по Хартри-Фоку. Для учета дисперсионных взаимодействий между слоями в кристалле в расчеты включена эмпирическая поправка Grimme. В результате моделирования нанотрубок различной хиральности и различных диаметров установлены минимальные диаметры одностенных нанотрубок, при которых сохраняется целостность химических связей на их внешней поверхности. Показано, что зависимость энергии сворачивания от диаметра удовлетворяет классическому закону обратных квадратов и одинакова для нанотрубок типов „зигзаг“ и „кресло“.
\end{abstract}

Ключевые слова: неорганические нанотрубки; полупроводники; халькогениды галлия; монослои; энергия сворачивания.

DOI: 10.21883 /FTT.2020.06.49346.023

\section{1. Введение}

Слоистые монохалькогениды галлия $\mathrm{Ga} X,(X=\mathrm{S}, \mathrm{Se})$ достаточно хорошо исследованы как экспериментально [1-4], так и теоретически [5-7]. Они обладают широким спектром практического применения, который определяется такими свойствами, как анизотропия структурных, оптических и электронных свойств. В частности, данные слоистые кристаллы вызывают большой интерес из-за возможного применения в оптоэлектронике [1] и в лазерной оптике в качестве материалов для быстрого преобразования частоты в THz- и ИК-диапазоны $[3,4]$. Ультратонкие кристаллы сульфида галлия $\mathrm{GaS}$ могут быть использованы в качестве высокочувствительных фотоприемников [2]. Полезные свойства данных полупроводниковых материалов могут быть модифицированы как путем допирования и интеркаляции различных атомов и молекул, так и переходом от объемных кристаллов к наносистемам. Слоистая структура рассматриваемых кристаллов обеспечивает возможность синтеза таких наноструктурированных систем как нанотрубки, наноленты и фуллерены.

Термодинамически стабильная гексагональная бетамодификация $2 H-\mathrm{GaS}$ принадлежит к пространственной группе $194 \mathrm{P6}_{3} / m m c$. Параметры кристаллической решетки составляют: $a=3.592 \AA, c=15.495 \AA$ [8]. В элементарной ячейке (ЭЯ) содержится 8 атомов, распределенных по двум монослоям, состоящим из 4-х чередующихся одноатомных плоскостей: $\mathrm{S}-\mathrm{Ga}-\mathrm{Ga}-\mathrm{S}$ (рис. 1). $\mathrm{B}$ первой координационной сфере атома галлия находятся три атома серы и один атом галлия, расстояние
$\mathrm{Ga}-\mathrm{Ga}=2.449 \AA$ [8]. Аналогичная модификация селенида галлия (II) $2 \mathrm{H}$-GaSe имеет такую же пространственную группу. Его параметры решетки: $a=3.750 \AA$, $c=15.995 \AA$, длина связи $\mathrm{Ga}-\mathrm{Ga}=2.444 \AA[9]$.

В настоящее время нанотрубки на основе халькогенидов галлия успешно синтезированы $[10,11]$. Так, имеется сообщение о синтезе многостенных трубок сульфида галлия (II) непосредственно из порошков серы и галлия [10]. Получены нанотрубки $\mathrm{GaS}$ и $\mathrm{GaSe}$, стабилизированные аминами [11]. Композитный материал на основе GaS, нанесенного на поверхность одностенных углеродных нанотрубок, является высокоэффективным анодом для литий-ионных батарей [12].

За последние годы опубликовано довольно много теоретических работ, посвященных расчетам геометрической, электронной и фононной структуры объемных кристаллов и монослоев монохалькогенидов галлия. В качестве примера, можно привести три недавние публикации [13-15]. Несмотря на достаточно большой объем экспериментальных данных, теоретические исследования нанотрубок на основе халькогенидов галлия ограничиваются несколькими работами. Среди них следует упомянуть квантовохимические расчеты, выполненные Enyashin, Seifert, и Tenne с соавт. в рамках полуэмпирического метода DFTB (Density-Functional Tight-Binding method) [16-18], основанного на теории функционала плотности (DFT). Неэмпирические расчеты нанотрубок $\mathrm{GaS}$ отсутствуют, а для GaSe имеется лишь один расчет [19], выполненный в рамках приближения локальной плотности (LDA). Данная работа направлена на то, 


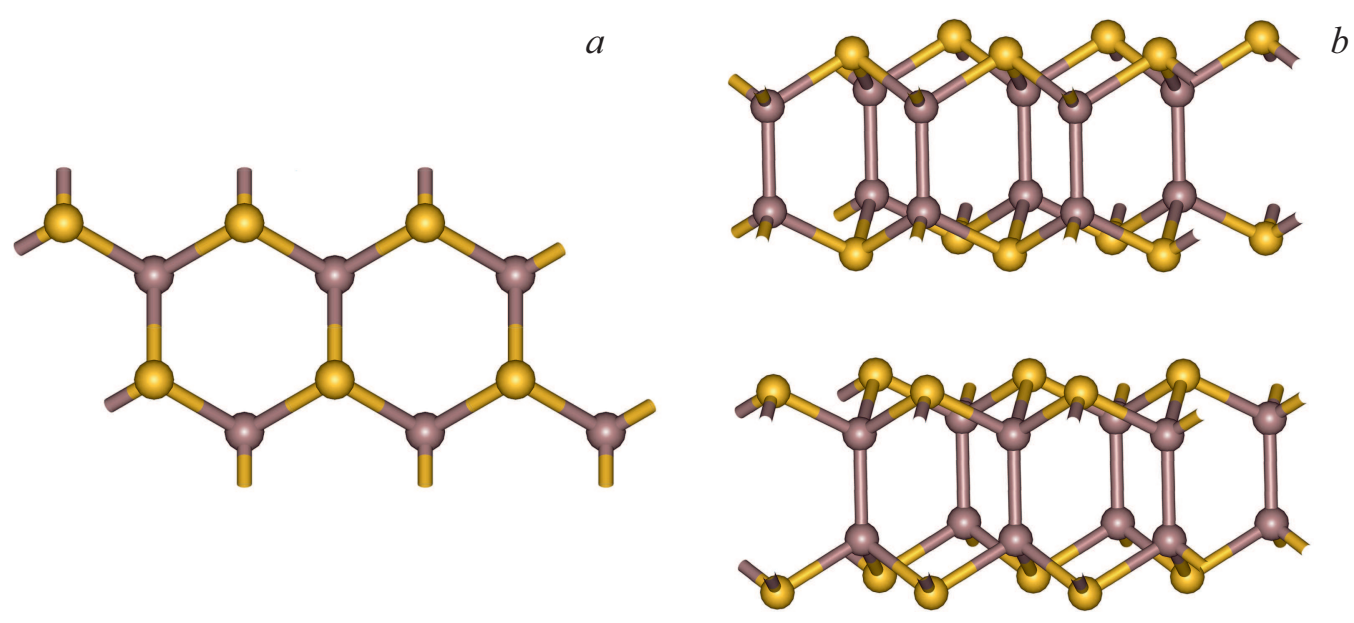

Рис. 1. Кристаллическая структура моносульфида галлия. $a$ : вид сверху (вдоль оси $c$ ), $b$ : вид сбоку. светлые сферы - атомы халькогена, более темные сферы - атомы галлия.

чтобы восполнить указанный пробел и с помощью теоретического моделирования изучить свойства упомянутых нанотрубок.

\section{2. Методика расчета}

Квантовохимические расчеты проведены в рамках гибридного варианта метода DFT (содержащего 13\% обмена по Хартри-Фоку) с использованием обменнокорреляционного функционала PBE [20]. В работе Кузьмина с соавт. [21] показано, что указанный гибридный функционал обеспечивает хорошее воспроизведение структурных, электронных и фононных свойств неорганических соединений.

Для описания одноэлектронных состояний в кристаллах, слоях и нанотрубках использовался валентнорасщепленный полноэлектронный базис гауссовых атомных орбиталей POB-DZVP_rev2 (версия 2019 г.) с удвоенным набором валентных функций и добавлением поляризационных функций, адаптированный для расчета твердотельных систем [22]. Расчет проводился по программе CRYSTAL17 [23]. В данной программе доступна так называемая „эмпирическая корректировка дисперсионных взаимодействий“, DFT-D3 [24], — с еe по- мощью возможен учет нековалентных (дисперсионных) взаимодействий, которые не могут быть воспроизведены посредством классического варианта DFT и которые играют важную роль в слоистых кристаллах. Для расчета указанной поправки мы использовали версию 2 с нулевым демпфированием на коротких расстояниях [25].

Генерация точек в зоне Бриллюэна (ЗБ) проводилась с использованием сетки Монхорста-Пака. В случае объемных гексагональных кристаллов и монослоев моносульфида и моноселенида галлия размер сетки составлял $16 \times 16 \times 4$ и $16 \times 16$ точек, соответственно. При расчете нанотрубок одномерная сетка содержала 12 точек. При вычислении решеточных сумм обменных и кулоновских интегралов были применены более строгие, по сравнению со значениями по умолчанию, критерии точности. Атомная структура объемных кристаллов, монослоев и нанотрубок полностью оптимизировалась.

В таблице оптимизированные параметры объемных кристаллов сравниваются с экспериментальными данными $[8,9]$ и результатами других расчетов [26,27], выполненных в базисе плоских волн.

Разница между экспериментальными и рассчитанными значениями не превышает $1 \%$, что позволяет считать методику, выбранную для квантовохимического модели-

Экспериментальные и рассчитанные параметры структуры объемных кристаллов $\mathrm{GaS}$ и $\mathrm{GaSe}$

\begin{tabular}{c|c|c|c|c|c|c|c}
\hline \multirow{2}{*}{$\begin{array}{c}\text { Параметры } \\
\text { решетки }\end{array}$} & $\begin{array}{c}\text { Эксперимент } \\
{[8]}\end{array}$ & $\begin{array}{c}\text { РВE } \\
{[26]}\end{array}$ & $\begin{array}{c}\text { Настоящая } \\
\text { работа }\end{array}$ & $\begin{array}{c}\text { Эксперимент } \\
{[9]}\end{array}$ & $\begin{array}{c}\text { PBE } \\
{[26]}\end{array}$ & $\begin{array}{c}\text { LDA } \\
{[27]}\end{array}$ & $\begin{array}{c}\text { Настоящая } \\
\text { работа }\end{array}$ \\
\hline & 3.592 & 3.630 & 3.617 & 3.750 & 3.755 & 3.662 & 3.773 \\
\hline$a, \AA$ & 15.465 & 15.701 & 15.496 & 15.995 & 15.898 & 15.587 & 16.006 \\
\hline $\begin{array}{c}r(\mathrm{Ga}-\mathrm{S}) \text { или } \\
r(\mathrm{Ga}-\mathrm{Se}), \AA\end{array}$ & 2.332 & & 2.367 & 2.453 & & & 2.478 \\
\hline$r(\mathrm{Ga}-\mathrm{Ga}), \AA$ & 2.449 & & 2.446 & 2.444 & & & 2.437
\end{tabular}



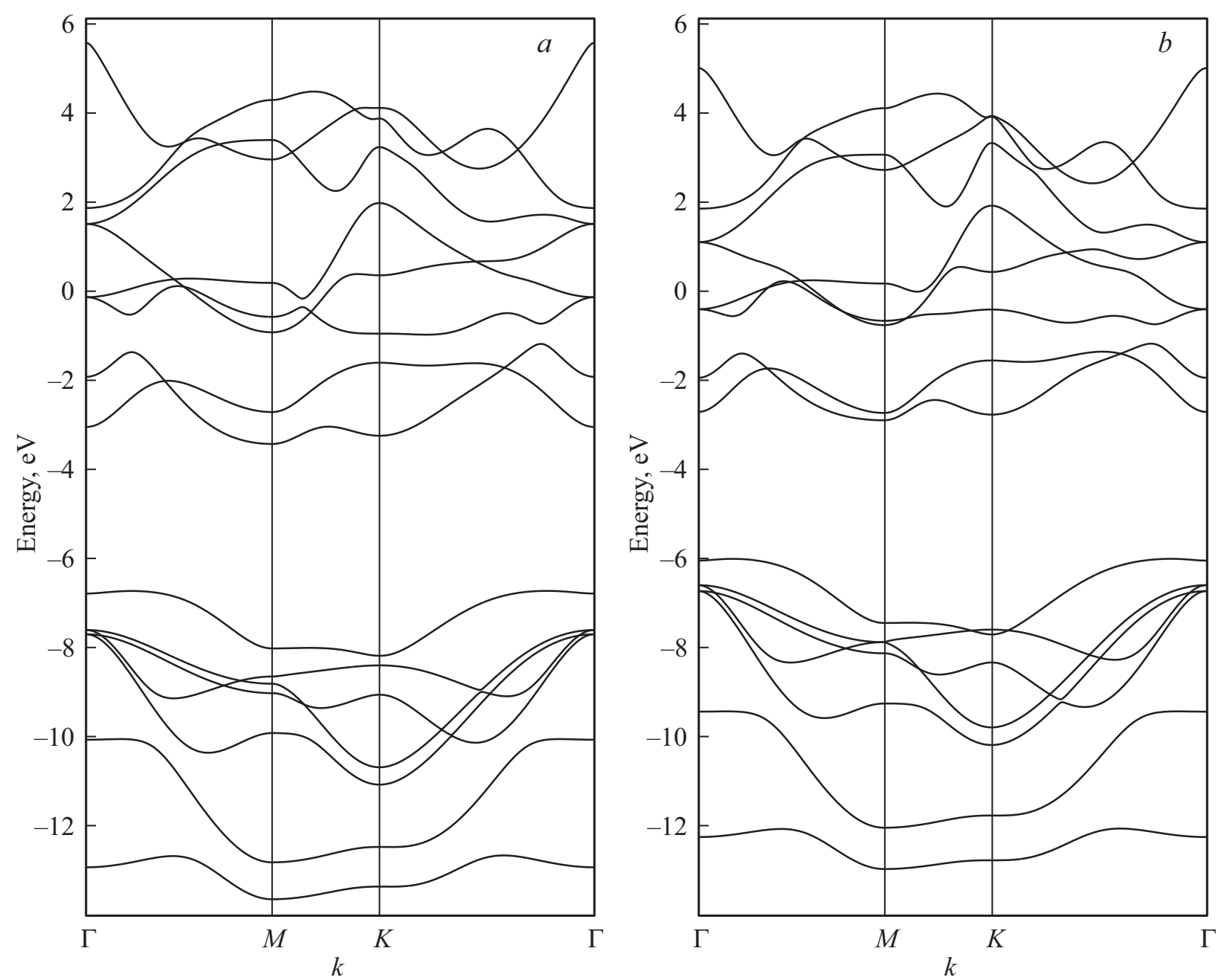

Рис. 2. Зонная структура электронных состояний монослоев $\mathrm{GaS}(a)$ и $\mathrm{GaSe}(b)$.

рования, подходящей в рамках поставленной задачи и использовать ее для расчета других систем на основе монохалькогенидов галлия.

Монохалькогениды галлия принадлежат к полупроводниковым материалам, поэтому в рамках данного моделирования были определены величины ширины запрещенной зоны, которая является непрямой. По нашим данным вершина валентной зоны находится в точке $\Gamma$, а дно зоны проводимости находится в точке М ЗБ, что вполне соответствует имеющимся литературным данным (см., например, недавнюю работу Hoat [15]). Для $\mathrm{GaS}$ она составила $2.27 \mathrm{eV}$, а для $\mathrm{GaSe}$ равна $1.98 \mathrm{eV}$. Полученные величины достаточно близки к экспериментальным данным: $\mathrm{GaS}-2.53 \mathrm{eV}$ [28], $\mathrm{GaSe}-2.01 \mathrm{eV}[29]$.

Структура монослоев, выделенных из бета-фазы, описывается слоевой группой рб$m 2$. Оптимизация геометрии изолированных монослоев показала, что их геометрическая структура меняется крайне незначительно по сравнению с исходной структурой в составе объемных фаз. Так длина связей $\mathrm{Ga}-\mathrm{Ga}$ при переходе от объем- ных кристаллов к монослоям увеличивается лишь на $0.004 \AA$ для $\mathrm{GaS}$ и на $0.002 \AA$ для GaSe. Рассчитанная энергия образования монослоев из объемного кристалла составляет $+12.7 \mathrm{~kJ} \cdot \mathrm{mol}^{-1}$ для $\mathrm{GaS}$ и $+11.7 \mathrm{~kJ} \cdot \mathrm{mol}^{-1}$ для $\mathrm{GaSe}$ (на одну формульную единицу).

На рис. 2 представлена электронная зонная структура монослоев, рассчитанная в данной работе. Максимум энергии состояний валентной зоны находится в точке Г (как и в объемном кристалле), а минимум энергии состояний зоны проводимости, по-видимому, находится на направлении ГK примерно в точке с координатами $(0.1,0.1,0)$, хотя очень близкое по энергии состояние имеется и на направлении ГM в точке с примерными координатами $(0.1,0,0)$. Полученные нами результаты хорошо согласуются с результатами ранее опубликованных расчетов [14-16] зонной структуры монослоев. Ширины непрямых запрещенных зон монослоев составляют $3.30(\mathrm{GaS})$ и $3.12(\mathrm{GaSe}) \mathrm{eV}$, что заметно больше соответствующих величин для объемных кристаллов. Этот эффект связан с так называемым „квантовым ограничением“ (quantum confinement [16]). 

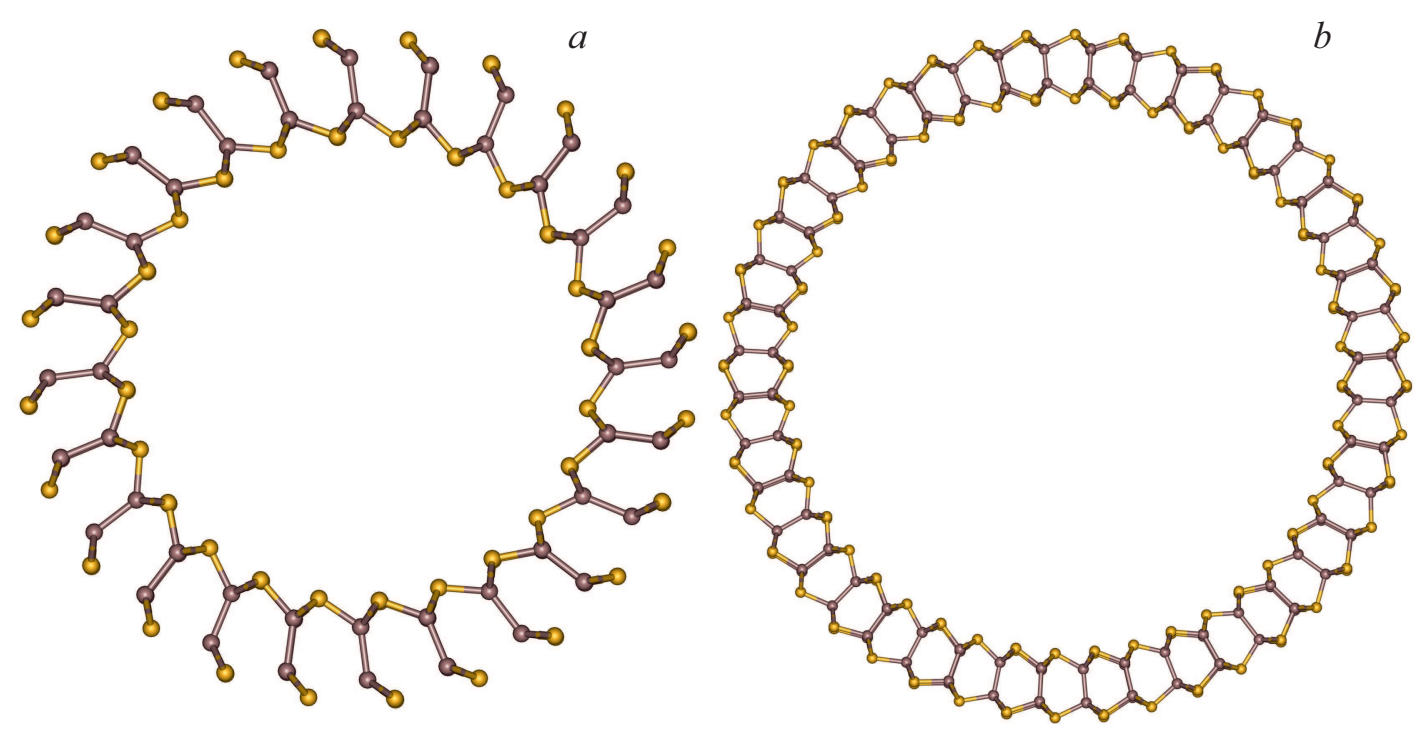

Рис. 3. Сечение оптимизированных нанотрубок $\operatorname{GaS}$ типа „кресло“ $(12,12)(a)$ и $\operatorname{GaS}(22,22)(b)$.
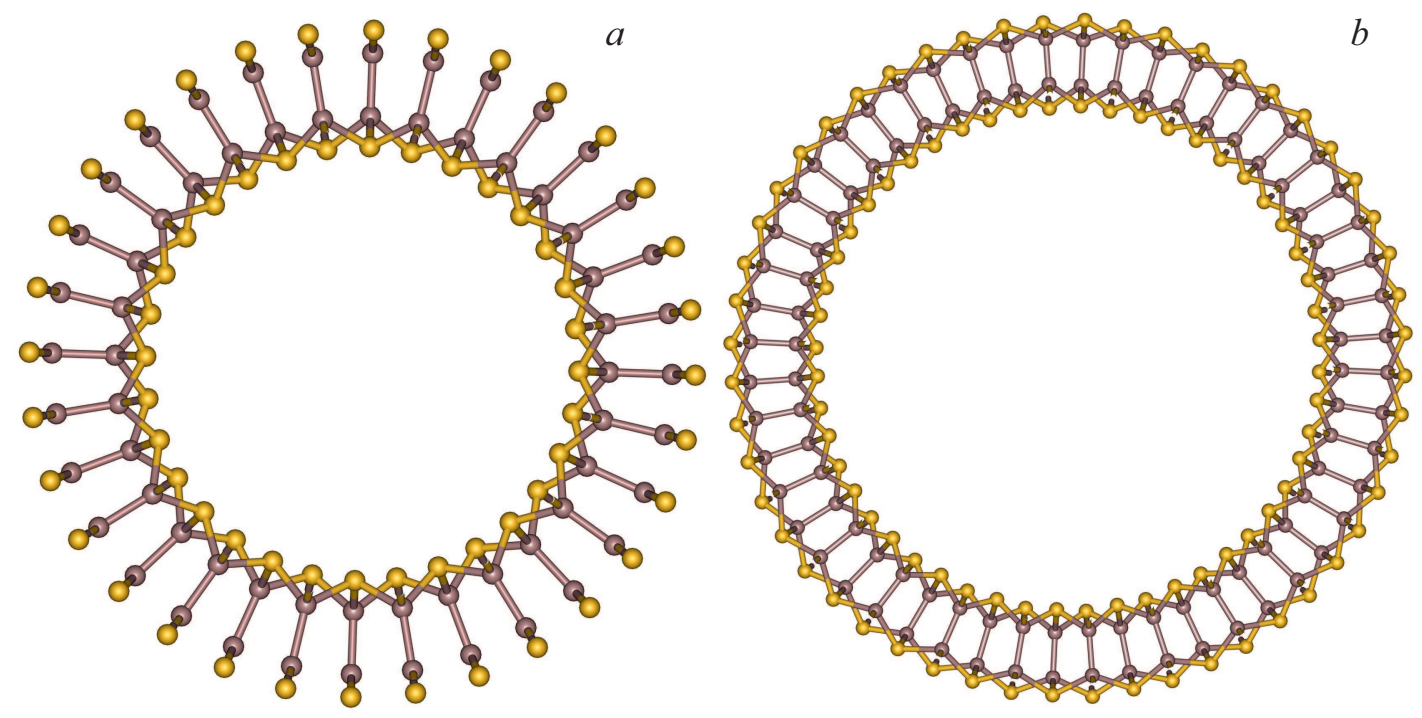

Рис. 4. Сечение оптимизированных нанотрубок $\mathrm{GaS}$ типа „зигзаг“ $(16,0)(a)$ и $\operatorname{GaS}(26,0)(b)$.

\section{3. Результаты расчетов нанотрубок}

Основное содержание данной работы составляют квантовохимические расчеты ахиральных нанотрубок типов ,зигзаг“ $(n, 0)$ и „кресло“ $(n, n)$, полученных сворачиванием монослоев сульфида галлия (II) и селенида галлия (II). Величина $n$ изменялась в пределах 18-38 для нанотрубок типа „зигзаг“ и 12-34 для нанотрубок типа „кресло“, что отвечает диаметрам 24-45 ̊ и $26-68 \AA$, соответственно. Диаметр нанотрубки $d$ вычислялся как сумма радиусов внутренней и внешней оболочек, образованных атомами халькогена.

Главным критерием стабильности нанотрубок является энергия сворачивания, $E_{\mathrm{str}}$. Эта величина рассчитыва- лась по формуле:

$$
E_{\mathrm{str}}=\frac{E_{\mathrm{NT}}}{N_{\mathrm{NT}}}-\frac{E_{\mathrm{mono}}}{N_{\mathrm{mono}}},
$$

где $E_{\mathrm{NT}}-$ общая энергия нанотрубки на одну ЭЯ, $N_{\mathrm{NT}}-$ количество формульных единиц в ЭЯ нанотрубки, $E_{\text {mono }}$ - общая энергия монослоя на одну ЭЯ, $N_{\text {mоnо }}$ - количество формульных единиц в ЭЯ монослоя.

При сворачивании и оптимизации геометрии поверхности нанотрубок малого диаметра $(d<23 \AA$ для $(n, 0)$ и $d<30 \AA$ для $(n, n))$ приобретают структуру, отличную от таковой для монослоя в результате разрыва связей $\mathrm{Ga}-\mathrm{S}(\mathrm{Se})$ на внешней поверхности. В настоящей работе это наблюдается у трубок $\mathrm{GaS}(12,12),(14,14)$ и 
GaSe $(12,12)$, а также у трубок $\operatorname{GaS}(16,0),(18,0)$ и $\mathrm{GaSe}(16,0)$ (см. рис. 3 и 4). Подобные деформации предшествуют полной потере целостности трубки с последующим разрушением других связей [16]. Можно принять, что допустимым является увеличение связей $\mathrm{Ga}-X(X=\mathrm{S}, \mathrm{Se})$ на $10 \%$ относительно расстояния, наблюдаемого в гексагональной бета-модификации. Для связи $\mathrm{Ga}-\mathrm{S}$ определенная таким образом максимальная длина составляет $\sim 2.6 \AA$, а для связи $\mathrm{Ga}-\mathrm{Se} \sim 2.7 \AA$. Эти значения близки к длине связи $\mathrm{Ga}-\mathrm{S}$ в метастабильной фазе кубического $\mathrm{GaS}: r(\mathrm{Ga}-\mathrm{S})=2.68 \AA$ [30]. Например, для трубки $\mathrm{GaS}(12,12)$, для которой наблюдается разрыв внешних связей, расстояния от любого атома серы до соседних двух атомов галлия для внутренней поверхности трубки (для направлений поперек и вдоль окружности нанотрубки) равны 2.30 и $2.34 \AA$. Аналогичные расстояния для внешней поверхности нанотрубки $(12,12)$ составляют 2.38 и $2.80 \AA$. В тоже время, соответствующие расстояния на внешней поверхности трубки $\operatorname{GaS}(22,22)$ равны 2.41 и $2.42 \AA$ (см. рис. 3$)$.

Зависимость энергии сворачивания от диаметра представлена на рис. 5 в координатах энергия сворачивания - квадрат обратного диаметра. Легко видеть, что приведенные зависимости имеют линейный характер, что соответствует классической теории эластичности [19]. Для сравнения на графике представлены результаты для нанотрубок $\mathrm{GaS}$, полученные в работе [17]. Несмотря на различные методы расчета, полученные нами величины лишь незначительно превосходят значения [17], найденные методом DFTB, что дополнительно свидетельствует о разумности полученных величин.

Энергии сворачивания нанотрубок селенида галлия (II) больше, чем $E_{\text {str }}$ сульфида при одинаковых диаметрах. Однако, энергии сворачивания нанотрубок разной хиральности почти не различаются. С ростом диаметра энергия сворачивания трубок стремится к 0 , оставаясь положительной при всех диаметрах.

Зависимости ширины запрещенной зоны от диаметра нанотрубки могут быть представлены в координатах ширина запрещенной зоны - обратный диаметр (рис. 6), поскольку, как показано в ряде работ [31,32], на этих графиках они могут иметь линейные участки. Как и в случае объемных кристаллов, ширина запрещенной зоны для нанотрубок моносульфида галлия больше по сравнению с селенидом. Ширина запрещенной зоны однозначно возрастает с ростом диаметра нанотрубок. В отличие от энергий сворачивания, полученные нами значения $E_{\text {gap }}$ для нанотрубок с разными хиральностями, располагаются на разных кривых, причем в случае нанотрубок типа „зигзаг“ значения меньше, чем в случае нанотрубок типа „кресло“. При этом для нанотрубок $\mathrm{GaS}(n, 0)$ и всех нанотрубок GaSe запрещенная зона - прямая. Для $\operatorname{GaS}(n, n)$ в случае малых $(d<26 \AA)$ и относительно больших диаметров $(d>50 \AA)$ наблюдается непрямая запрещенная зона, а для нанотрубок промежуточных диаметров минимальная ширина соответствует прямому переходу. Величины $E_{\text {gap }}$ для трубок $\mathrm{GaS}$, найденные

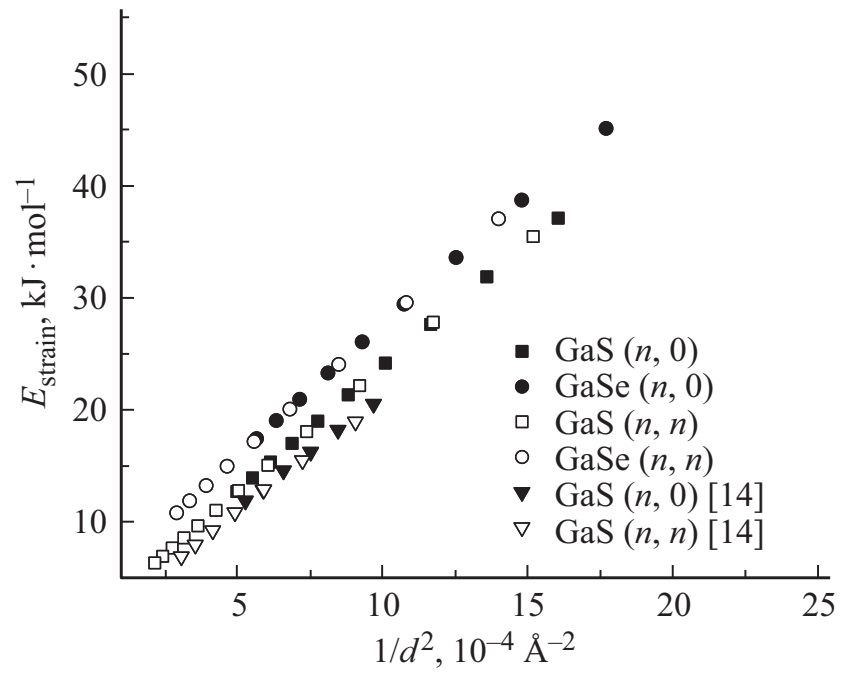

Рис. 5. Зависимость энергии сворачивания нанотрубок $\mathrm{GaS}$ и $\mathrm{GaSe}$ от квадрата обратного диаметра. Аппроксимация уравнением вида $E=k / d^{2}+b$ определяется следующими коэффициентами: для $\mathrm{GaS} k=2.227 \cdot 10^{4} \mathrm{~kJ} \cdot \AA^{2} \cdot \mathrm{mol}^{-1}$ и $b=1.677 \mathrm{~kJ} \cdot \mathrm{mol}^{-1}$, для GaSe $k=2.334 \cdot 10^{4} \mathrm{~kJ} \cdot \AA^{2} \cdot \mathrm{mol}^{-1}$ и $b=4.276 \mathrm{~kJ} \cdot \mathrm{mol}^{-1}$.

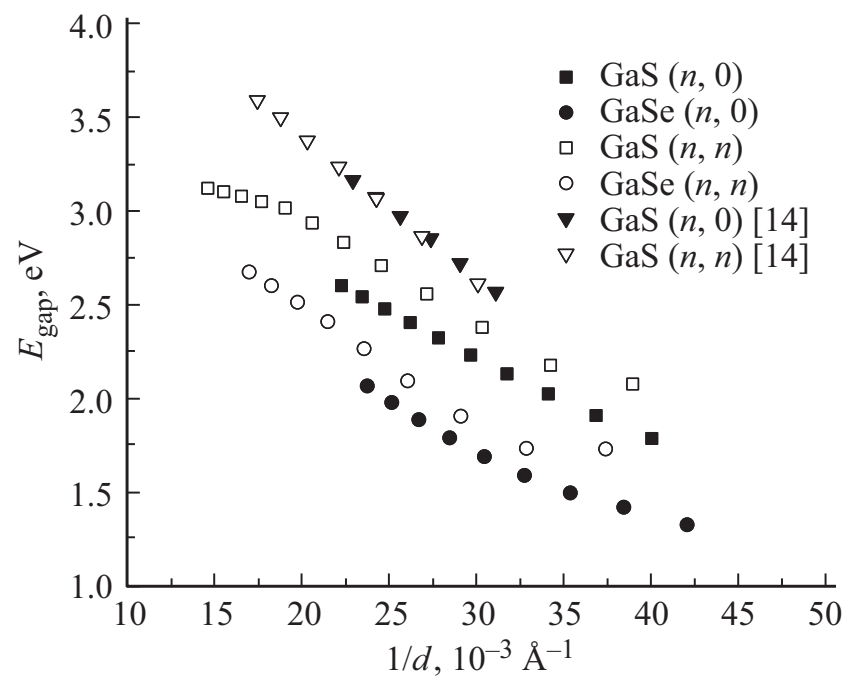

Рис. 6. Зависимость ширины запрещенной зоны нанотрубок $\mathrm{GaS}$ и $\mathrm{GaSe}$ от обратного диаметра.

в предыдущей работе [17], слегка превышают наши значения. Энергии сворачивания нанотрубок на основе селенида галлия, рассчитанные в работе [19], превышают полученные нами в два раза, что может быть связано с использованием приближения LDA, которое не всегда корректно передает энергию образования.

\section{4. Заключение}

В настоящей работе выполнены неэмпирические квантовохимические расчеты нанотрубок на основе монослоев сульфида и селенида галлия (II). Используемые 
в расчетах функционал плотности, базис и параметры дисперсионных взаимодействий достаточно точно передают структуру объемных кристаллов. Диапазон рассчитанных значений ширины запрещенной зоны нанотрубок позволяет отнести их к полупроводниковым материалам. Значение $E_{\text {gap }}$ возрастает при увеличении диаметра нанотрубки и стремится к ширине запрещенной зоны монослоя. Значение энергии сворачивания довольно быстро уменьшается при увеличении диаметра нанотрубки и становится меньше $10 \mathrm{~kJ} \cdot \mathrm{mol}^{-1}$ при диаметрах порядка $50 \AA(\mathrm{GaS})$ или $60 \AA(\mathrm{GaSe})$, что заметно превышает аналогичные величины для углеродных нанотрубок. Однако, как и в случае других нанотрубок с гексагональной симметрией исходных монослоев [32,33], энергии сворачивания не зависят от типа нанотрубок, а зависят только от их диаметра и хорошо аппроксимируются классической линейной зависимостью от обратного квадрата диаметра.

Выполненные нами расчеты подтверждают принципиальную возможность синтезирования одностенных нанотрубок на основе халькогенидов Ga. Для полной оценки стабильности нанотрубок необходим расчет фононных частот и оценка энтальпии образования, что планируется в дальнейшем. Логично предположить, что стабильность указанных нанотрубок может быть заметно увеличена при сворачивании разноповерхностных монослоев, образованных смешанными халькогенидами GaSSe, как это имеет место для смешанных халькогенидов Мо и $\mathrm{W}$ [33]. Результаты соответствующих расчетов являются предметом планируемых публикаций.

\section{Конфликт интересов}

Авторы заявляют, что у них нет конфликта интересов.

\section{Финансирование работы}

Исследование выполнено при финансовой поддержке РФФИ в рамках научного проекта № 20-0300271 и с использованием вычислительных ресурсов Ресурсного Центра „Вычислительный центр СПбГУ“ (http://www.cc.spbu.ru/).

\section{Список литературы}

[1] K.A. Yee, T.A. Albright. J. Am. Chem. Soc. 113, 6474 (1991).

[2] J. Martinez-Pastor, A. Segura, J.L. Valdes, A. Chevy. J. Appl. Phys. 62, 1477 (1987).

[3] X. Zhou, J. Cheng, Y. Zhou, T. Cao, H. Hong, Z. Liao, S. Wu, H. Peng, K. Liu, D. Yu. J. Am. Chem. Soc. 137, 7994 (2015).

[4] S. Das, C. Ghosh, O.G. Voevodina, Yu.M. Andreev, S.Yu. Sarkisov. Appl. Phys. B 82, 43 (2006).

[5] D. Errandonea, A. Segura, F.J. Manjón, A. Chevy, E. Machado, G. Tobias, P. Ordejón, E. Canadell. Phys, Rev. B 71, 125206 (2005).

[6] 3.А. Джахангирли. ФТТ 54, 1024 (2012).

[7] H.R. Jappor. Physica B 524, 109 (2017).
[8] A. Kuhn, A. Bourdon, J. Rigoult, A. Rimsky. Phys. Rev. B 25, 4081 (1982).

[9] S. Benazeth, N.-H. Dung, M. Guittard, P. Laruelle. Acta Crystallogr. C 44, 234 (1988).

[10] P.A. Hu, Y.Q. Liu, L. Fu, L.C. Cao, D.B. Zhu. Appl. Phys. A 80, 1413 (2005).

[11] A. Seral-Ascaso, S. Metel, A. Pokle, C. Backes, C.J. Zhang, H.C. Nerl, K. Rode, N.C. Berner, C. Downing, N. McEvoy, E. Muñoz, A. Harvey, Z. Gholamvand, G.S. Duesberg, J.N. Coleman, V. Nicolosi. Nanoscale 8, 11698 (2016).

[12] X. Meng, K. He, D. Su, X. Zhang, C. Sun, Y. Ren, H.-H. Wang, W. Weng, L. Trahey, C.P. Canlas, J.W. Elam. Adv. Funct. Mater. 24, 5435 (2014).

[13] 3.А. Джахагшиоди, Ф.М. Гашизаде, Д.А. Гусейнова, Б.Г. Мехтиев, Н.Б. Мустафаев. ФТТ 58, 1707 (2016).

[14] H.L. Zhuang, R.G. Hennig. Chem. Mater. 25, 3232 (2013).

[15] D.M. Hoat. Phil. Mag. 99, 736 (2019).

[16] A.N. Enyashin, O. Brontvein, G. Seifert, R. Tenne. Isr. J. Chem. 57, 529 (2017).

[17] T. Köhler, T. Frauenheim, Z. Hajnal, G. Seifert. Phys. Rev. B 69, 193403 (2004).

[18] D. Porezag, T. Frauenheim, T. Köhler, G. Seifert, R. Kaschner, Phys. Rev. B 51, 12947 (1995).

[19] M. Côté, M.L. Cohen, D.J. Chadi. Phys. Rev. B 58, 4277(R) (1998).

[20] J.P. Perdew, K. Burke, M. Ernzerhof. Phys. Rev. Lett. 77, 3865 (1996).

[21] A. Kuzmin, A. Kalinko, R.A. Evarestov. Cent. Eur. J. Phys. 9, $502(2011)$

[22] D.V. Oliveira, J. Laun, M.F. Peintinger, T. Bredow. J. Comput. Chem. 40, 2364 (2019).

[23] R. Dovesi, A. Erba, R. Orlando, C.M. Zicovich-Wilson, B. Civalleri, L. Maschio, M. Rerat, S. Casassa, J. Baima, S. Salustro, B. Kirtman. WIREs Comput. Mol. Sci. 8, 1360 (2018).

[24] S. Grimme, J. Antony, S. Ehrlich, H. Krieg. J. Chem. Phys. 132, 154104 (2010).

[25] S. Grimme, S. Ehrlich, L. Goerigk. J. Comp. Chem. 32, 1456, (2011).

[26] D. Wickramaratne, F. Zahid, R.K. Lake. J. Appl. Phys. 118, 075101 (2015).

[27] D.V. Rybkovskiy, N.R. Arutyunyan, A.S. Orekhov, I.A. Gromchenko, I.V. Vorobiev, A.V. Osadchy, E.Yu. Salaev, T.K. Baykara, K.R. Allakhverdiev, E.D. Obraztsova. Phys. Rev. B 84, 085314 (2011).

[28] C.H. Hoa, S.L. Lin. J. Appl. Phys. 100, 083508 (2006).

[29] M. Gauthier, A. Polian, J.M. Besson, A. Chevy. Phys. Rev. B 40, 3837 (1989).

[30] A.N. MacInnes, M.B. Power, A.R. Barron. Chem. Mater. 4, 11 (1992).

[31] M. Staiger, P. Rafailov, K. Gartsman, H. Telg, M. Krause, G. Radovsky, A. Zak, C. Thomsen. Phys. Rev. B. 86, 165423 (2012).

[32] A.V. Bandura, R.A. Evarestov. Surf. Sci. 641, 6 (2015).

[33] R.A. Evarestov, A.V. Kovalenko, A.V. Bandura. Physica E 115, 113681 (2020).

Редактор Ю.Э. Китаев 